\title{
Presídias dos terceiros do Carmo de Vila Rica: territorialidade e rede confraternal em Minas Gerais,
} 1744-1848

\author{
Presídias of third order of Carmo from Vila Rica: territoriality and the order \\ network in Minas Gerais, 1744-1848
}

Francisco Eduardo de Andrade*

\begin{abstract}
Resumo
A pesquisa trata da configuração institucional da Ordem Terceira do Carmo da capital políticoadministrativa do território minerário, Vila Rica ou Ouro Preto, através das suas filiais, as presídias (presidências locais), cuja disseminação ultrapassou os limites da capitania/província de Minas Gerais, no interior brasileiro. As presídias forneceram à sede-matriz da Ordem Terceira rendimentos acrescidos (pagamentos, doações, concessões) que não eram acessíveis às irmandades reduzidas a uma jurisdição paroquial. As filiais da Ordem foram os dispositivos fundamentais de integração local dos associados (agentes do comércio ou emigrados) e da instituição da fraternidade, com papel destacado nas alianças de amizade e de parentesco. Essa associação religiosa de abrangência territorial, justaposta à teia de freguesias das Minas (matrizes e capelas), conformou uma elite político-econômica e as identidades dos agentes de poder (brancos, senhores, autoridades políticas, militares), contribuindo para forjar noções de pertencimento comunitário e de reconhecimento de grupo (conforme o estamento). Através da difusão das presídias, ademais, pode-se apreender o mercado dos bens simbólicos relacionados às práticas devocionais carmelitanas.
\end{abstract}

Palavras-chave: Ordem Terceira do Carmo; Fraternidade; Território; Presídia.

\begin{abstract}
The research deals with the institutional configuration of the Third Order of Carmo in the politicaladministrative capital of the mining territory, Vila Rica or Ouro Preto, through its subsidiaries, the presídias (local presidencies), whose dissemination has been overcome the boundaries of the captaincy / province of Minas Gerais, in the interior of Brazil. The presídias provided increased incomes to the headquarters of the Third Order (payments, donations, concessions) that were not accessible to that fraternities which were reduced to parochial jurisdiction. The Order's subsidiaries were fundamental devices which provided local integration of the associates (trade agents or emigrants) and fraternity stablishment, with highlighted role in the alliances based on friendship and kinship. This religious association of territorial coverage, and the network of parishes in Minas Gerais (mother churches and chapels), contributed to the creation of a political-economic elite and to the identities of the power agents (white people, lords, political authorities, military), contributing as well to forge notions of community belonging and group recognition (according to the estate). Through the diffusion of the presídias, in addition, one can seize the market of symbolic goods related to carmelite's devotional practices.
\end{abstract}

Keywords: Third Order of Carmo; Fraternity, Territory; Presídia.

Artigo submetido em 25 de julho de 2018 e aprovado em 8 de agosto de 2019.

* Doutor em História. Professor da UFOP. País de origem: Brasil. E-mail: franciscoeandradeop@gmail.com

Horizonte, Belo Horizonte, v. 17, n. 53, p. 1170-1193, maio/ago. 2019 - ISSN 2175-5841 


\section{Introdução}

A dispersão estrutural dos moradores e a fluidez populacional, em articulação com os ritmos econômicos operados pelos poderes políticos, contribuem para explicar a fundação, em poucos anos (entre 1740 e 1761), de quatro Ordens terceiras no território de Minas Gerais, onde antes só havia terceiros do Carmo subordinados às associações de outras capitanias da América portuguesa $^{1}$. Criaram-se associações carmelitas de leigos nos núcleos urbanos mais dinâmicos: Vila de São João Del Rei, Vila Rica, Mariana (cidade episcopal), Tejuco (arraial da comarca diamantífera) e Vila de Sabará. ${ }^{2}$

Evidentemente, o culto a Nossa Senhora do Carmo é bem anterior a essas datas e o proselitismo devocional seguramente foi protagonizado por frades carmelitas, atuantes no território das Minas, e por emigrados, que eram terceiros nos lugares de origem - outras capitanias como São Paulo, Rio de Janeiro, Bahia, Pernambuco ou Portugal (PRAT, 1941, p. 15). Quando teve início os famosos descobrimentos de ouro, o padre descobridor João de Faria Fialho, vigário da vila de Taubaté (na rota de São Paulo e de São Vicente), na década de 1690, pretendeu reger uma capela que dedicou a Nossa Senhora do Carmo, no local dos ricos depósitos auríferos (SANTA MARIA, tomo 10, p. 184-185; 234; 245-246). Outro indício significativo das preferências de invocação é a povoação intitulada, a partir de 1711, Vila do Carmo, local de residência do governador da nova capitania de São Paulo e Minas do ouro; fora antes o "Arraial do distrito do Ribeirão de Nossa Senhora do Monte do Carmo”, topônimo resultante de outra capela fundada nas imediações das lavras. 3

\footnotetext{
${ }^{1}$ Sobre as Ordens Terceiras de Minas Gerais, conferir Evangelista (2010), Mendonça (2015), Souza (2015), Barbosa (2015), Silveira (2017), Gomes (2009). Sobre a pretensão de afrodescendentes, no contexto da mestiçagem, à Ordem Terceira, ver Precioso (2014).

${ }^{2}$ Ver Passos (1940, p. 11-13), Lopes (1942, p. 5), Trindade (1958, p. 37), Salles (2007, p. 186-189), Boschi (1986, p. 214-224). No livro de "conta corrente e receita", da Ordem Terceira do Carmo de Vila Rica, já se indicaria um irmão associado à Ordem em 1744; conferir Neves; Cotta (2010, p. 75).

${ }^{3}$ Conforme o termo de junta de eleição camarária de 1711 (KANTOR, 1998, p. 151).
} 
Observam-se as ramificações costumeiras da fraternidade em lugares urbanos consolidados, como a vila de São João Del Rei e Vila Rica. Seguramente, alguns terceiros moradores das vilas, cujas relações com a praça portuária do Rio de Janeiro eram intensas, filiavam-se à Ordem Terceira desta cidade. Mas eles pretenderam fundar associações autônomas, embora mantivessem sua subordinação à mesma Província carmelita. Os terceiros desses núcleos interioranos seriam membros das presídias - ou presidências - subordinadas à associação terciária da cidade litorânea.

A capacidade de criar e de administrar as presídias, criadas em diversos lugares ou localidades (ou mesmo em bairros citadinos), foi o suporte fundamental da expansão terciária e do vigor econômico da associação-matriz do Carmo do território colonial. No entanto, muito pouco se sabe a respeito desse mecanismo e do papel que exerceria na manutenção da Ordem Terceira e, ainda, pouco se perguntou sobre as dimensões políticas, econômicas e sociais de um dispositivo institucional que estava vedado às outras confrarias, especialmente às dos pobres, mestiços ou negros. Considerou-se o estabelecimento efetivo de uma associação terciária (Ordem Terceira de São Francisco de Vila Rica) quando havia presídias, isto é, "vice-comissariados ou filiais [...] em quase todas as paróquias e em muitas capelas do bispado" (TRINDADE, 1958, p. 8). Assim, os historiadores do fenômeno confraternal observaram empiricamente a relevância das presidências/filiais, mas as interpretações conceberam o funcionamento e as relações corporativas, o desempenho dos dirigentes, as inversões religiosas, culturais, sociais e econômicas, assim como as expressões devocionais dos terceiros somente no âmbito da matrizsede que congregaria, fundamentalmente, os irmãos supostamente avizinhados da urbe. 4

\footnotetext{
${ }^{4}$ Fritz Salles, expoente de uma história social das irmandades mineiras (anos 1960), para quem a Ordem Terceira do Carmo congregava a classe dos comerciantes, assinalou: "O que caracteriza a feição grupal e de defesa dos interesses dos diversos estamentos sociais é a ligação que as irmandades estabeleciam, como se fosse uma rede, através das cidades" (SALLES, 2007, p. 132). Contudo, o autor não se desvinculou do espaço convencional da dinâmica confraternal - no âmbito de cada cidade dita histórica, gênese da singular cultura barroca -, que se tornou recorrente na história cultural e social das confrarias.
} 
Caio Boschi, na sua pesquisa de síntese do fenômeno associativo leigo das Minas da América portuguesa, advertiu (em nota), após apresentar uma lista das "irmandades coloniais mineiras":

o prestígio e crescimento [das Ordens Terceiras] estavam na razão direta da extensão de suas presídias, verdadeiras filiais que se disseminavam por todo o território da Capitania, e às vezes até fora dele, cujo número total é impossível de se estabelecer com exatidão. (BOSCHI, 1986, p. 204-205). 5

O historiador considerou, apreendendo o pronunciado regalismo português da segunda metade do século XVIII, que as Ordens Terceiras resistiram à vigilância da Coroa quanto à duplicidade de irmandades congêneres no mesmo lugar ou vila, e às imposições canônicas (que previam uma distância superior a três milhas para criação de confraria semelhante). Assim, as presídias teriam fornecido "a fórmula para fugir a essas determinações. Aliás, [...] deram às mesmas [Ordens Terceiras] um caráter universalista, contrariamente às [simples] irmandades" (BOSCHI, 1986, p. 27). ${ }^{6}$ O estudioso, infelizmente, não aprofundou as implicações institucionais e sociais desses mecanismos de urdidura da rede terciária.

Pode-se observar que, enquanto essas poderosas associações terciárias dos brancos pretenderam, a partir da sua lógica hierárquica de funcionamento e do voto de obediência, concentrar os recursos e as decisões na Venerável Ordemmatriz, cujas filiais multiplicaram-se, as irmandades dos pretos do Rosário dividiam-se e rompiam os laços com a irmandade primordial. Nessa divisão, podia ocorrer até uma mudança da invocação principal dos devotos negros ou mestiços, devido às diferenças sociais (ou étnicas), às rivalidades das corporações religiosas e, ainda, às disposições canônicas e régias. A administração episcopal não admitia mais de uma confraria do mesmo gênero (e devoção) na mesma paróquia e, assim, embora houvesse proliferação das irmandades do Rosário, cada uma tinha uma mesa dirigente própria (ANDRADE, 2016).

\footnotetext{
${ }^{5}$ Esse autor estendeu o espaço territorial onde eram forjadas as confraternidades, não se reduzindo às associações dos núcleos urbanos supostamente representativos da história regional.

${ }^{6}$ A conclusão surge, ainda, em nota.
} 
A historiografia mais recente tampouco investigou os dispositivos terciários mantenedores de capital econômico, social e simbólico, embora algumas pesquisas tenham notado as suas implicações.7 Ao invés do termo presídia - usual na documentação dos terceiros carmelitas e franciscanos na capitania de Minas Gerais e, particularmente, de Vila Rica-, encontra-se, nos textos portugueses da regulação confraternal da Ordem do Carmo, a designação de presidências, como locais da atuação dos presidentes. Esses agentes avisavam os irmãos sobre os funerais e, notadamente, arrecadavam as taxas e as esmolas dos irmãos moradores nos bairros citadinos ou nas freguesias (ENCARNAÇÃO, 1685, p. 118-119; SANTA ANA, 1745, Tomo 1, p. 616; 618).

Nos estatutos da Ordem Terceira do Carmo de Lisboa (1715), havia, em conformidade com a regra, a função do "presidente", "que consistia em cobrar as esmolas”. No reino, os presidentes foram mencionados nas disposições de precedência das procissões públicas organizadas pelos terceiros do Carmo, mas não assumiam os papéis destacados que eram conferidos aos oficiais da mesa dirigente 8 (BAYÓN, 2001, p. 494; 500-501; 549).

\section{Os terceiros de Vila Rica e as presídias}

A Ordem Terceira do Carmo do Rio de Janeiro, cuja rede confraternal estendeu-se às Minas Gerais, tinha suas presidências (MARTINS, 2009, p. 148; 322-324). No entanto, estas não tiveram o papel-chave que desempenharam nas associações terciárias fundadas no território minerário. Sobretudo, a Ordem Terceira do Carmo de Vila Rica (ou cidade de Ouro Preto, a partir de 1823), entre os séculos XVIII e XIX, foi bastante eficiente na fundação de presídias e na sua

\footnotetext{
${ }^{7}$ Ver Souza $(2015$, p. 120, 127, 141, 183-184). Sobre as presidências, Barbosa (2015, p. 140) somente concluiu: “uma especificidade das Ordens Terceiras de São Francisco mineiras era a presença em sua administração dos irmãos presidentes. Não há relatos da existência dessa função em Braga, Rio de Janeiro e São Paulo. Como a OTSFM tinha um raio de atuação que abrangia várias freguesias de seu entorno, era necessário eleger um irmão responsável por cobrar esmolas, avisar os irmãos sobre atividades na Capela da Ordem e vigiar a conduta em rincões distantes da Capela. [...] Os requisitos para investidura no cargo são distintos dos considerados para o grupo de irmãos servidores - exigia-se a 'limpeza de mãos' e a abundância de bens, além do letramento".

${ }^{8} \mathrm{Na}$ cidade de Braga ou na vila/cidade de São Paulo, não existia, de acordo com os estatutos da Ordem Terceira de São Francisco (1742), a função de presidente ou as circunscrições das presidências (MORAES, 2009, p. 95-106, 366-382).
} 
administração proveitosa. De acordo com os estatutos dessa confraria, estabelecidos em 1755, os irmãos presidentes, nas suas presídias, subordinavam-se à mesa administrativa terciária, em Vila Rica, que seria a instância de governo “político e temporal” e espiritual, com a seguinte composição: prior, superior (um subprior), secretário, definidores (10), tesoureiro, procurador, zelador (que serviria também de enfermeiro) e um sacerdote comissário da Religião do Carmo (Ordem Primeira) (ACCOP, OTCOP, Estatutos, 1755, volume 2418, microfilme 199, capítulo 1).9 Estipularam-se as obrigações dos presidentes, ligadas à economia da corporação:

\begin{abstract}
Devem ser estes irmãos que a Mesa conhecer, serem muito verdadeiros, limpos de mãos, boa consciência e que saibam ler, escrever e contar [...], e outrossim devem ser de boa condição, benévolos e muito corteses, para que não escandalizem os Irmãos de quem houverem de cobrar, e na Vila serão repartidos pelos bairros, ou ruas e por fora nas distâncias dela haverá em cada freguesia um, a quem o irmão secretário terá cuidado de remeter a lista dos irmãos que houver em cada uma das presídias da Vila, e freguesia das distâncias dela, na qual se lhe declarará o que cada hum irmão está devendo, e anuais de uma oitava e quarto por ano e o mais que deverem atrasados, e serão os ditos presidentes obrigados a fazer as ditas cobranças, e as mais que pertencerem a Ordem: e de tudo o que cobrarem e forem cobrando, o virão entregar em Mesa, para se fazer carga ao irmão tesoureiro do que receber; e também serão os ditos irmãos presidentes obrigados a apresentarem as listas que se lhe mandaram, para por elas se dar descarga aos irmãos que pagaram, tendo o irmão secretário cuidado logo naquele ato pôr tudo com clareza a que não hajam dúvidas. (ACCOP, OTCOP, Estatutos, 1755, capítulo 11).
\end{abstract}

Os presidentes tornaram-se, nos estatutos, os mediadores entre a mesa e a comunidade local da fraternidade. Eram os informantes dos oficiais da mesa (procurador ou secretário) e das comunidades das presídias, quando se tratava de assistência aos doentes (material e espiritual) e dos falecimentos. Os "presidentes das freguesias de fora" (além dos limites da urbe) determinavam o amparo coletivo aos irmãos enfermos e vigiavam a continuidade das ações caritativas. Ademais, os presidentes alertavam os confrades para participarem dos funerais e dos ritos da

\footnotetext{
${ }^{9}$ Arquivo da Casa dos Contos de Ouro Preto [doravante ACCOP], Paróquia de Nossa Senhora do Pilar, Ordem Terceira de Nossa Senhora do Carmo de Ouro Preto [doravante OTCOP]. Haveria, ainda, sem integrar a mesa, "cabeça de toda a Ordem": um mestre de noviços, dois vigários do culto divino (que se reduziu para um na reforma), quatro sacristães, um ou dois andadores. No segmento feminino, fundamental, haveria uma priora, subpriora e uma mestra de noviças. Os estatutos compreenderam 35 capítulos, cujos capítulos 1 , 2 , $3,4,13,18,20,21,29,35$ foram reformados por decisão provincial no Rio de Janeiro.
} 
Ordem. Por outro lado, esses dirigentes das presídias informavam ao governo do sodalício os casos de confrade que "padece alguma necessidade", "para a mesa prover" (ACCOP, OTCOP, Estatutos, 1755, capítulo 9, artigo 2; capítulo 11, artigos 1, $2,3)$.

No regimento terciário, os procedimentos de fiscalização da arrecadação dinheiro das entradas, anuais, taxas, esmolas e doações dos irmãos - e das despesas - sufrágios e serviços fúnebres, cerimônias e festas, construções, ornamentações, assistência caritativa - foram bem definidos. Houve a preocupação em evitar possíveis desvios e malversações dos recursos angariados. Por isso, a conferência da economia do sodalício integrava diferentes agentes, o que permitiria apontar contradições da escrituração e criar dificuldades aos conluios. Assim, as anotações contábeis dos presidentes ("que hão de servir também de cobradores" dos irmãos listados pelo secretário em cada presídia) deviam corresponder aos lançamentos do livro do tesoureiro, na matriz da Ordem. Os livros dos presidentes e do tesoureiro, ainda, podiam ser examinados pelo procurador, que, parecendolhe "conveniente", solicitava ao prior que determinasse a revisão, ou a reforma das contas (livros da receita e despesa) (ACCOP, OTCOP, Estatutos, 1755, capítulo 8, artigo 8; capítulo 7; capítulo 25, artigo 2).

Para manter a rede de informações, e forjar o agenciamento supostamente eficaz da corporação, a mesa dirigente podia empregar até dois irmãos andadores. Nos estatutos de 1755, determinou-se que deviam ser "cristãos velhos e limpos de geração, o que se deve examinar" e "ser capaz de guardar segredo, inteligente para bem servir, e para este efeito, de idade competente, que saiba ler, e escrever se for possível, e será verdadeiro e muito inteligente" (ACCOP, OTCOP, Estatutos, 1755, capítulo 12, artigo 2). As características dos andadores, que parecem prever a fidelidade aos interesses corporativos, o manejo cuidadoso das informações e o desembaraço na mobilidade, eram fundamentais nesses executores da comunicação entre a "cabeça" da Ordem Terceira e as suas presídias. 
A necessidade de oferecer os serviços espirituais e promover os ritos terciários impôs a criação da figura do vice-comissário em cada presídia, principalmente quando essa integrasse uma paróquia forânea. Comumente, o pároco local assumia o cargo, porque o comissariado dos terceiros do Carmo era atividade prestigiosa e, parece, lucrativa, o que atraiu o clero secular das localidades. A mesa do sodalício do Carmo de Vila Rica, conforme o privilégio concedido pelo Padre Geral da Ordem Primeira em Roma, pretendeu escolher o seu comissário (considerado uma espécie de capelão empregado pela confraria), cuja eleição não dependeria da administração da província carmelita. Mas, a direção provincial, no Rio de Janeiro, alegou ter a prerrogativa de eleger o comissário, cuja dignidade elevava-se a de prelado, e que à mesa caberia somente a indicação (ACCOP, OTCOP, Estatutos, 1755, Reforma do capítulo 3).

O vice-comissário não era um agente previsto no regimento setecentista dos terceiros do Carmo de Vila Rica, mas a sua função exigia desempenhar um papel análogo ao do comissário. Conforme os estatutos, o comissário era um sacerdote professo da Ordem, eleito pela mesa para exercer "toda a jurisdição sobre o espiritual”, que significava as atividades de valor pastoral: conceder os hábitos dos novos membros (noviços) e dirigir as profissões dos irmãos, oficiar as missas, realizar as cerimônias tradicionais da Ordem, assistir aos funerais, administrar os sacramentos - comunhão, confissão e penitência -, nomear os cargos femininos, doutrinar conforme a regra carmelita e a catequese católica (ACCOP, OTCOP, Estatutos, 1755, capítulo 3). Se não pudesse exercer o seu papel, ele podia delegar "os seus poderes" a um ou "mais sacerdotes irmãos para acudirem as necessidades espirituais". Os vice-comissários das presídias seriam esses eclesiásticos substitutos, já admitidos nos estatutos (ACCOP, OTCOP, Estatutos, 1755, capítulo 3, artigo 9). Em outra versão dos estatutos da Ordem, datada do final dos oitocentos, mencionou-se a figura do eclesiástico vice-comissário, que, juntamente 
com o presidente, admitiam, depois de informados, os fiéis qualificados que quisessem integrar a Ordem. ${ }^{10}$

Os presidentes e os vice-comissários, com efeito, tornaram-se responsáveis nos povoados do território pelo ingresso dos vizinhos à fraternidade. As atribuições desses ampliaram-se, certamente, na medida em que houve a disseminação das presídias, no contexto de expansão das fronteiras econômicas e das mudanças institucionais da Ordem Terceira (efeito, por exemplo, da proibição legal de segregar pela infâmia de cristão novo), entre o final do século XVIII e o século seguinte. ${ }^{11}$ Os administradores da presídia deviam (para atender as disposições da fiscalização da Coroa) enviar procurações assinadas pelos ingressantes ou professos, que representassem as entradas ou profissões, à mesa confraternal, cujo secretário, mediante essas comunicações reconhecidas pelos administradores e apresentadas pelos procuradores, fazia o registro dos irmãos nos livros da Ordem (AEPNSPOP, OTCOP, Livro Presídia de Nossa Senhora da Conceição da Aplicação de Claudio, 1807). No entanto, parece que essa prática de envio de procurações para registro, na matriz, dos irmãos noviços e professos das presídias, não se consolidou. De qualquer maneira, os secretários da Ordem insistem na obrigação, no século XIX, de envio de "notas firmadas" pelos vice-comissários e presidentes, "do dia, mês e ano da entrada, e profissão, e da quantia respectiva por que foram admitidos” (AEPNSPOP, OTCOP, Livro Presídia São Bartolomeu, 1846).

Os dirigentes pretenderam, ainda, organizar a escritura contábil e a relação dos irmãos das presídias por meio de livros dos presidentes, que apresentavam as “contas correntes" dos confrades assistidos pelo sodalício, com o registro periódico das dívidas e dos pagamentos. Cada presídia teria seu livreto e, uma vez por ano, estaria obrigada a remeter à matriz, onde haveria a conferência dos seus registros e

\footnotetext{
${ }^{10}$ Nesses estatutos de 1879, determinou-se, provavelmente com a intenção de coibir a descentralização das decisões concernentes à matriz terciária, em Vila Rica, que a criação ou a extinção das presídias era uma prerrogativa da mesa administrativa (NEVES; COTTA, 2010, p. 101).

${ }^{11}$ As leis portuguesas, promovidas pelo ilustrado Marquês de Pombal, como a de 25 de maio de 1773 (além das determinações régias de liberdade e dos direitos políticos indígenas, em 1755), visavam abolir os critérios tradicionais de descendência portuguesa (pureza), e de cristãos velhos (limpeza de sangue), mas a sua efetividade deve ser bastante relativizada, pelo menos até o início do século XIX; ver Souza (2015, p. 86-87), Barbosa (2015, p. 287-288). Contudo, a escravidão africana, com seus efeitos sociais, foi o fundamento do vigor das práticas de distinções étnicas e sociais.
} 
os traslados necessários à escrituração dos livros da Ordem (AEPNSPOP, OTCOP, Livro Presídia de Nossa Senhora da Conceição da Aplicação de Claudio, 1807). No entanto, provavelmente, na maioria das presídias, não havia esses livros de contas, cuja escrituração simples apresentava, na mesma lista, a soma das dívidas e a subtração dos pagamentos de cada associado. ${ }^{12}$

Os rendimentos das presídias estavam previstos nas usuais listas de cobrança, elaboradas pelo secretário da mesa do sodalício. Esse as enviava aos presidentes, encarregados de dispor os pagamentos, ajustar as contas e entregar o montante do dinheiro arrecadado ao andador, que também conferia as anotações (AEPNSPOP, OTCOP, Livro Presídia de Nossa Senhora da Conceição da Aplicação de Claudio, 1807). As listas das presídias, devolvidas à mesa dirigente (tesoureiro e secretário), faziam o cômputo dos pagamentos efetuados pelos confrades e do seu endividamento (como também dos dispêndios da assistência espiritual ou material prestada pela Ordem aos associados).

\section{Uma rede confraternal}

A associação terciária carmelita de Vila Rica foi criada em 1744, de acordo com um quadro estatístico da confraria elaborado pela sua administração e datado de 1842. Desde a década de 1740, embora pudesse ligar-se, na forma de presídia, aos terceiros do Rio de Janeiro, a associação fundada na urbe governamental da capitania das Minas já constituía, segundo o quadro estatístico, os seus ramos de presídias. Parecia claro aos contemporâneos que sem a organização quase imediata dessa rede não se consolidariam os poderes político-religioso e econômico da Ordem terciária. As fundações das filiais, com efeito, repercutem a expansão das fronteiras econômicas da capitania minerária. As presídias da Ordem teriam sido fundadas, desde 1747-1748, principalmente nas povoações ou paróquias da comarca de Vila Rica, inclusive na cidade Mariana (AEPNSPOP, OTCOP, Mapa da

\footnotetext{
${ }^{12}$ Não se usava, supõe-se, fazer uma avaliação periódica da lucratividade da presídia. Aliás, conferiu-se que "a contabilidade de entrada simples [único assento de receita ou de despesa] continuava a ser usada por muitos negociantes europeus na primeira metade do século XIX", pois "eles não tinham por hábito extrair balanços frequentes" (PEDREIRA, 1996, p. 377). Agradecemos à professora Cláudia Chaves a indicação do artigo.
} 
estatística pessoal da Venerável Ordem Terceira de Nossa Senhora do Monte do Carmo da imperial cidade de Ouro Preto até o ano de 1842). Mesmo que a associação não tivesse uma existência efêmera, sem tais alicerces, poderia tornar-se um instituto cujas atividades ou serviços ficariam marcados pela instabilidade.

Entre os séculos XVIII e XIX, a grande maioria dos confrades, homens e mulheres, morava nas povoações das presídias, disseminadas no espaço territorial, em distância de mais de duas léguas (13.200m) das duas paróquias centrais de Vila Rica. Afinal, essa era a distância que se cogitara para definir o término do período de noviciado, nos estatutos: os noviços "sendo moradores na Vila, ou nos seus arrabaldes duas léguas em redondo, professem dentro de oito dias" (ACCOP, OTCOP, Estatutos, 1755, capítulo 14, artigo 2); pois, nesse âmbito, o deslocamento dos confrades até a capela não exigia uma longa jornada de viagem.

As presídias dos terceiros do Carmo de Vila Rica expandiram-se, nas décadas de 1740 e 1750, na mesma comarca e, ainda, na comarca do Rio das Velhas (ou da Vila de Sabará), que além da extração minerária, vinculava-se expressivamente às atividades agropastoris. ${ }^{13} \mathrm{~A}$ partir da década de 1780 , no entanto, acentuaram-se as fundações de presídias na comarca do Rio das Mortes (ou de São João del Rei), cujo dinamismo econômico (abastecimento de gêneros e tratos mercantis), correlato ao aumento demográfico, contribuiu para a difusão da devoção do Carmo e a sua articulação à prestigiosa Ordem em Vila Rica. Pode-se admitir o interesse dos dirigentes da fraternidade em ampliar o raio da sua influência e de concessão dos seus serviços e privilégios (ou dons) no território, nas comarcas de Rio das Mortes e de Paracatu (cruzadas pelas rotas mercantis), que poderiam oferecer maiores rendimentos ao sodalício. Sabe-se que, no contexto econômico e demográfico da segunda metade dos setecentos e do início dos oitocentos, a comarca de Vila Rica - ou o núcleo urbano, sobretudo - sofreu os efeitos do refluxo da mineração aurífera, com a diminuição da produção agrária e

\footnotetext{
${ }^{13}$ AEPNSPOP, OTCOP, Mapa da estatística pessoal [...] até o ano de 1842; ver Carrato (1968). Trata-se de proposta de divisão territorial das comarcas, com localização das vilas-sedes de comarcas, vilas, cidade-sede do bispado, sedes das varas eclesiásticas, sedes paroquiais, e indicações das produções econômicas em cada comarca, no início do século XIX. Essas, embora sejam elucidativas, ainda são claramente insuficientes.
} 
demográfica, enquanto as comarcas do Rio das Mortes e do Rio das Velhas (que incluía o território da freguesia de Paracatu, caminhos de Goiás e de Tocantins), mais populosas, tiveram as suas produções agropecuárias e os negócios mercantis acrescidos. ${ }^{14}$

Os dons terciários carmelitas - entre os quais, as concessões espirituais como as indulgências parciais ou plenárias -, ou o capital político-religioso, significavam a identificação performativa dos confrades com a ascendência portuguesa (pureza de sangue) e a condição social das elites políticas - agentes do governo camarário ou régio, autoridades eclesiásticas - ou econômicasnegociantes, mercadores e senhores de terras e escravos. ${ }^{15}$ Relacionada, notadamente, aos membros da mesa dirigente e aos presidentes dos lugares dessa confraria de pessoas brancas, a representação da qualidade social (origem familiar, conduta e posição) dos seus agentes instituía (com legitimidade) uma elite dos vizinhos ou a forma de nobreza plasmada nas práticas sociais, políticas e religiosas do território colonial. ${ }^{16}$ Considerando as patentes de oficiais militares dos dirigentes moradores das presídias, observa-se que eram escolhidos para as funções da mesa administrativa os irmãos professos mais proeminentes do lugar. Contudo, nas presídias, embora houvesse um número significativo de presidentes que ostentassem o título de alferes (oficial de baixa patente), outros presidentes eram oficiais mais graduados, como tenente ou capitão, as patentes relativamente mais mencionadas quando se tratavam dos confrades que exerceram o cargo de prior. ${ }^{17}$ Possivelmente, nas filiais situadas no termo municipal de Vila Rica, que

\footnotetext{
${ }^{14}$ Ver: Quadro 65, em Carrara (1997, p. 194); tabela 1: Minas - população das comarcas entre 1776 e 1835, em Cunha (2007, p. 139); mapa 7 (produção de gêneros) e mapa 13 (casas de negócio estabelecidas em 1836), em Anexos, de Paiva (1996). Em 1776, registrou-se que as populações das comarcas do Rio das Velhas (99.576) e do Rio das Mortes (82.781) eram maiores do que o número de habitantes da comarca de Vila Rica (78.618), onde a produção aurífera, concentradora dos trabalhadores africanos, fora a mais elevada, dentre as comarcas, na primeira metade do século XVIII (VEIGA, 1998, p. 732).

${ }^{15}$ Conforme o enquadramento sociológico proposto por Bourdieu (2007, p. 48), "os leigos não esperam da religião apenas justificações de existir capazes de livrá-los da angústia existencial da contingência e da solidão, da miséria biológica, da doença, do sofriment o ou da morte. Contam com ela para que Ihes forneça justificações de existir em uma posição social determinada, em suma, de existir como de fato existem, ou seja, com todas as propriedades que lhes são socialmente inerentes".

${ }^{16} \mathrm{Na}$ acepção apresentada por Heinz $(2006$, p. 8), que cita a proposição de Christophe Charle, "as elites são definidas pela dete nção de certo poder ou então como produto de uma seleção social ou intelectual, e o estudo das elites seria um meio para determinar 'quais os espaços e os mecanismos do poder nos diferentes tipos de sociedade ou os princípios empregados para o acesso às posições dominantes'”. Definem-se, ainda, pela pretensão, na visão oligárquica, de possuir, exclusivamente, a consciência do devir histórico e, assim, são habilitados ao protagonismo da (re)criação do mundo social (BUSINO, 1992, p. 4-8).

${ }^{17}$ Estimativa baseada nos registros dos confrades dos livros de presídias (AEPNSPOP, OTCOP, Livros de Presídias, 1805-1860; CRUZ, 2015).
} 
reuniam dezenas ou centenas de confrades, o desempenho do papel de presidente, apesar de não ser ocupação da mesa dirigente, promovia o candidato ao governo da Ordem. Quase a metade dos priores, entre 1752 a 1825, participou da fraternidade através das presídias, onde alguns deles, talvez, tenham feito a sua profissão dos votos, definidos na regra carmelita, de obediência e de castidade segundo o seu estado (solteiro ou casado). O uso de procuradores para tomar posse do cargo foi um recurso utilizado por esses ausentes e, ainda, admitido pela Ordem que planejava a sua "utilidade". ${ }^{18} \mathrm{O}$ prior eleito para governar a confraria entre 1820 e 1821, Romualdo José Monteiro de Barros, por exemplo, morador na freguesia de Congonhas do Campo (termo municipal de Vila Rica), foi um rico minerador, sócio em fábrica de ferro e fazendeiro, que tomou posse por seu procurador. Irmão professo desde 1795 e oriundo da presídia de Congonhas, Barros, que foi agraciado com o título de Cavaleiro da Imperial Ordem de Cristo, parece ter sido um integrante de prestígio da rede de aliança terciária. Embora tivesse um custodoações e apoio exemplar aos irmãos desassistidos -, o papel do dirigente da corporação favoreceu, assim como o desempenho da função de vereador da câmara de Vila Rica, a sua trajetória política ascendente, bem sucedida no Brasil imperial, quando alcançou o governo da província e obteve o título de barão de Paraopeba. ${ }^{19}$

Entre o século XVIII e a primeira metade do século XIX, a fraternidade terciária de Ouro Preto, enraizada no território, estabeleceu uma rede com mais de cem filiais, constituída, sobretudo, nas comarcas do sul da capitania (e da província), que eram cruzadas pelas rotas de circulação mercantil intensa, como o caminho novo, a ligação primordial com o porto do Rio de Janeiro, e os diversos caminhos e atalhos de acesso às capitanias de São Paulo e de Goiás. ${ }^{20}$ Em geral, associaram-se ao sodalício mais homens do que mulheres. Ao mesmo tempo, a

\footnotetext{
${ }^{18}$ Figura de distinção e "cabedal" na fraternidade, que, de acordo com os estatutos, devia ter exercido outras ocupações da mesa antes da eleição de prior. Esperava-se, principalmente, que esse concedesse benefícios ou esmolas avultadas à Ordem: “Deve também ser nobre por geração ou pelo trato de que viver, de sorte que se siga maior respeito e autoridade, não entendemos, porém de excluir de poder ser eleito em prior, aquele irmão que for oficial [de alguma arte], quando da dita eleição da sua pessoa, redunde à Ordem alguma utilidade [aumento dos bens e sufrágios]" (ACCOP, OTCOP, 1755, capítulo 2).

${ }^{19}$ Ver Neves; Cotta (2010, p. 230).

${ }^{20}$ Haveria 130 presídias ou lugares de residência de confrades, no território da província de Minas Gerais (e até além dos seus limites político-administrativos), conforme o cálculo da Ordem terciária de Ouro Preto (AEPNSPOP, OTCOP, Mapa da estatística pessoal [...] até o ano de 1842).
} 
grande maioria dos confrades não pagou todos os débitos impositivos de entrada, taxa anual e profissão. No entanto, foi variável a proporção entre os gêneros nos diferentes lugares que integraram, no século XVIII e início do século seguinte, as cinco comarcas do território minerário (Tabela 1). Enquanto na cidade de Ouro Preto somente $30 \%$ dos confrades era do sexo feminino, em Oliveira - filial que congregou o maior número de confrades dentre as presídias instituídas na comarca do Rio das Mortes, sudoeste da capitania das Minas -, as mulheres superavam largamente os homens, alcançando 60\% do total dos confrades locais. Nessa presídia de Oliveira, localizada em comarca de movimento mercantil vigoroso, nos setecentos e no início da centúria seguinte, nota-se o interesse relativamente mais acentuado em liquidar os débitos, o que configurava uma situação oposta à da filial do Tejuco (ou vila de Diamantina, a partir de 1831) ou da Vila do Príncipe, na mesma comarca do Serro Frio, com uma alta concentração de homens e a negação absoluta de quitação das contas. ${ }^{21}$

A preponderância de confrades do sexo feminino também ocorreu na filial da extremidade ocidental da capitania de Minas Gerais, Araxá, instituída na comarca de Paracatu, cujo território limitava-se com a capitania de Goiás. Porém, nesse lugar ou povoado de Araxá, o número de terceiros que ainda deviam à Ordem (seguramente por falta de quitação dos anuais e da profissão) era muito elevado, comparável ao que se observou na presídia mais feminina de Pitangui e na matriz, em Ouro Preto. Do mesmo modo, na povoação de Paraopeba, situada na rota entre o território minerário e o oeste agropastorial da capitania, cuja fundação fora anterior à autorização eclesiástica carmelita da instituição terciária de Vila Rica (1751), o número de mulheres superou o dos homens e a quantidade dos devedores era semelhante a da sede, na capital, lugar de concentração de irmãos. Nos lugares distantes dos antigos núcleos da mineração setecentista de ouro ou dos diamantes - situados nas comarcas de Vila Rica e do Serro Frio - houve nítido predomínio das irmãs, principalmente, nos lugares dos itinerários dos negociantes e viajantes

\footnotetext{
${ }^{21}$ A respeito das divisões econômicas e ocupacionais do espaço provincial de Minas, que remontaram ao período de auge da extração aurífera no território, conferir Libby (1998).
} 
(Oliveira, Araxá), embora nem sempre houvesse o empenho delas na quitação constante dos débitos atribuídos pela fraternidade (Tabela 1). Assim, um predomínio feminino, ou masculino, não parece ser determinante do grau de vinculação institucional ou da fidelidade às obrigações confraternais numa presídia. As atitudes dos dois sexos, quanto à prestação de contas em cada filial, reproduziam a tendência coletiva local, definida pela comunidade com seus laços de parentesco, amizade e vizinhança.

TABELA 1

Confrades das maiores presídias, por comarca, fundadas na capitania de Minas Gerais [1842]

\begin{tabular}{|c|c|c|c|c|c|c|c|c|c|c|c|c|}
\hline \multicolumn{13}{|c|}{ Comarcas e lugares de moradia } \\
\hline \multirow[b]{2}{*}{ Confraria } & \multicolumn{2}{|c|}{ Capital/ matriz } & \multicolumn{2}{|c|}{ Ouro Preto } & \multicolumn{2}{|c|}{ Rio das Velhas } & \multicolumn{2}{|c|}{ Rio das Mortes } & \multirow{2}{*}{$\begin{array}{c}\text { Paracatu* } \\
\text { Araxá } \\
(1815)^{* *}\end{array}$} & \multicolumn{3}{|c|}{ Serro Frio } \\
\hline & $\begin{array}{c}\text { Ouro } \\
\text { Preto } \\
(1744)^{* *}\end{array}$ & $\%$ & $\begin{array}{l}\text { Piedade do } \\
\text { Paraopeba } \\
(1748)^{* * *}\end{array}$ & $\%$ & $\begin{array}{l}\text { Pitangui } \\
(1752)^{* *}\end{array}$ & $\%$ & $\begin{array}{l}\text { Oliveira } \\
(1766)^{* *}\end{array}$ & $\%$ & & $\%$ & $\begin{array}{l}\text { Tejuco } \\
(1757)^{* *}\end{array}$ & $\%$ \\
\hline $\begin{array}{l}\text { homens } \\
\text { mulheres }\end{array}$ & $\begin{array}{c}1458 \\
614\end{array}$ & $\begin{array}{l}70,4 \\
29,6\end{array}$ & $\begin{array}{l}141 \\
165\end{array}$ & $\begin{array}{l}46,1 \\
53,9\end{array}$ & $\begin{array}{l}136 \\
162\end{array}$ & $\begin{array}{l}45,6 \\
54,4\end{array}$ & $\begin{array}{l}124 \\
189\end{array}$ & $\begin{array}{l}39,6 \\
60,4\end{array}$ & $\begin{array}{c}93 \\
127\end{array}$ & $\begin{array}{l}42,2 \\
57,8\end{array}$ & $\begin{array}{l}57 \\
07\end{array}$ & $\begin{array}{l}89,1 \\
10,9\end{array}$ \\
\hline $\begin{array}{l}\text { confrades } \\
\text { de contas } \\
\text { justas }\end{array}$ & 380 & 18,3 & 53 & 17,3 & 38 & 12,8 & 76 & 24,3 & 18 & 8,2 & OO & OO \\
\hline $\begin{array}{l}\text { confrades } \\
\text { devedores }\end{array}$ & 1692 & 81,7 & 253 & 82,7 & 260 & 87,2 & 237 & 75,7 & 202 & 91,8 & 64 & $\begin{array}{c}100, \\
0\end{array}$ \\
\hline Total & 2072 & 100 & 306 & 100 & 298 & 100 & 313 & 100 & 220 & 100 & 64 & 100 \\
\hline
\end{tabular}

*Comarca criada em 1815, cuja divisão incorporou parte do território da capitania de Goiás. Nos limites das comarcas do Rio das Mortes e de Paracatu, localizava-se a presídia de Franca, na capitania/ província de São Paulo: 198 confrades (81 irmãos e 117 irmãs).

** data de fundação.

Fonte: AEPNSPOP, OTCOP, Mapa da estatística pessoal [...] até o ano de 1842.

Em Ouro Preto, de acordo com o cálculo de 1842, moravam algumas centenas de membros pagadores, o que revela a atração exercida pela sede jurisdicional no âmbito da confraternidade (Tabela 1). Todavia, desde o século XVIII, a matriz não conseguia manter a fábrica aumentada da capela, os serviços espirituais e a assistência estatutária aos confrades pobres ou aos doentes sem os recursos provenientes da rede de presídias. $\mathrm{O}$ apelo à rede era essencial ao custeio dos planos construtivos do seu templo, cuja ornamentação devia expressar a dignidade ou o decoro terciário, e das edificações necessárias ao funcionamento do 
sodalício - o consistório, a casa do noviciado, os recintos da fábrica da capela (objetos de culto e paramentos) e da escrituração contábil usual ou "do despacho" (com seu mobiliário e arquivo) (LOPES, 1942, p. 11-12). ${ }^{22}$ Se esses planos arquitetônicos e artísticos foram efetivados pela Ordem Terceira do Carmo de Vila Rica, isso se deveu à eficiência da corporação em disseminar a religiosidade carmelita, sustentação dos privilégios espirituais e sociais, desde os primeiros anos da sua fundação.

Entre 1766 e o final da década de 1850 - desde os alicerces, a construção da capela-mor e dos seis altares colaterais até o douramento do retábulo e do teto do consistório - o templo foi erguido e ornado, fundamentalmente, segundo os preceitos estilísticos do rococó. Os terceiros construíram o seu templo no mesmo local da capela da irmandade de Santa Quitéria, que conviera com a Ordem Terceira para a demolição da antiga capela e a construção do novo templo dedicado a Nossa Senhora do Carmo (LOPES, 1942, p. 19-25; 67-80; 91-92). É bem provável que contribuiu, decisivamente, para esse ajuste, a entrada, na Ordem do Carmo, de membros poderosos da antiga irmandade, como um dos fundadores da irmandade de Santa Quitéria, o capitão-mor Antônio Ramos dos Reis, rico dono de lavras na vila, eleito prior em 1760 (no mesmo ano em que ocupou a função de provedor da prestigiosa irmandade paroquial do Santíssimo Sacramento). Poucos anos depois da sua administração, alcançou-se um acordo entre as corporações estabelecidas na mesma capela, mas que terminava por sujeitar, por completo, a antiga devoção. 23

Os confrades mobilizaram-se para a construção da capela particular do sodalício. Afirmou-se, em estudo que investigou a documentação da Ordem, que a mesa administrativa "distribuiu cadernos de assentos para registro das esmolas" que “devem ter sido entregues aos representantes das presídias”. A mesa dispôs,

\footnotetext{
${ }^{22}$ Os estatutos de 1755 dispunha que o cofre seria conservado na casa do tesoureiro, para evitar risco de roubo (AEPNSPOP, OTCOP, capítulo 7, artigo 2).

${ }^{23}$ Conferir Neves; Cotta (2010, p. 153). Sobre Ramos dos Reis, ver Oliveira (2016, p. 85, 149-150, 170, 182). A trajetória social desse privilegiado parece corroborar o processo histórico do enquadramento social conferido pelas irmandades de Minas, proposto por Fritz Salles, cuja interpretação, porém, soa reducionista: membro da antiga irmandade do Santíssimo Sacramento, que teria congregado reinóis comerciantes e antigos conquistadores paulistas no início do século XVIII, Reis fundou, talvez no final da década de 1710, o sodalício de membros portugueses (antagônicos aos sesmeiros paulistas) de Santa Quitéria, e, décadas depois, no contexto de estratificação social, tornou-se membro da Ordem Terceira do Carmo, que se identificaria aos interesses dos comerciantes inseridos, em grande parte, no mercado interno (SALLES, 2007, p. 101-117).
} 
“entre 1755 e 1777, cerca de vinte e quatro cadernos, contendo promessas e recebimentos de doações em ouro, para a construção da Igreja” (NEVES, 2010, p. 158). Nas décadas seguintes, persistiu-se no recurso aos pedidos de esmolas para custear as obras ou melhorias na edificação da capela-sede da Ordem. Uma lista de benfeitores da capela, ainda, foi promovida pelo governador-prior dom Rodrigo que, no início da década de1780, pediu aos fiéis que fizessem doações "para a fatura da talha dos altares da capela”. Contribuíram 84 pessoas e arrecadou-se 2:162\$209 (como citado em Lopes, 1942. p. 76-75). Valor considerável, se tomar como parâmetro o preço do escravo artífice, na segunda metade do século XVIII, que foi avaliado entre $120 \$ 000$ e $150 \$ 000$ réis (CAMPOS, 2013, p. 125).

Para realmente contribuírem para as finanças da Ordem, os confrades deviam persistir na coexistência devocional, de acordo com o calendário litúrgico e as condutas difundidas pelo comissariado da Ordem, pela mesa administrativa e pelos presidentes, pois, se os associados não eram membros ativos, nem muito estimulados aos ganhos corporativos, tornavam-se negligentes nos pagamentos. $\mathrm{Na}$ verdade, a extensão da rede ligava-se, também, a esse predomínio de devedores nos bairros, arraiais e freguesias. De modo geral, agrupando todas as contas dos terceiros do conjunto examinado - 33 filiais com anotações de contas -, observa-se o acúmulo dos débitos. ${ }^{24}$ Algumas presídias, porém, fizeram pagamentos bem mais constantes, como a da paróquia de Santa Bárbara, fundada na comarca do Rio das Velhas em 1751, cujos associados pagaram 50\% do total previsto de receita (AEPNSPOP, OTCOP, Livro Presídia de Santa Bárbara, 1807). ${ }^{25}$

O valor total das dívidas dos associados, que, supostamente, eram membros atuantes da confraria (ou que não estivessem ausentes por qualquer motivo), foi praticamente equivalente à quantia total do dinheiro recolhido pelos presidentes (ou por andadores), embora os pagamentos tenham superado ligeiramente os débitos (cf. AEPNSPOP, OTCOP, Livros de Presídias, 1805-1848). Mas, se

\footnotetext{
${ }^{24}$ Há anotações contábeis, no arquivo da Ordem do Carmo, de 46 presídias (AEPNSPOP, OTCOP, Presídias, 1805-1860).

${ }^{25}$ Preocupação incomum com o endividamento foi observada na presídia de Casa Branca, fundada na comarca de Vila Rica em 1754, onde os confrades pagaram quase $80 \%$ do cálculo da receita - caso, talvez, de registros de contas mais realistas (AEPNSPOP, OTCOP, Livro Presídia Casa Branca, 1860).
} 
considerarmos as receitas contábeis das presídias, ou seja, os rendimentos esperados, ou prometidos, desde as entradas dos devotos na fraternidade, os pagamentos efetuados sequer equivaleram a um terço do montante do dinheiro que a Ordem deveria receber nessas presídias (32:943\$508 réis). ${ }^{26}$

Mesmo assim, a quantia efetivamente arrecadada (9:964\$578 réis) era apreciável, comparando-se com o valor de um escravo artesão, acima mencionado. O montante do dinheiro enviado à matriz da Ordem em Vila Rica pode ter sido, nas primeiras décadas do século XIX, três a quatro vezes maiores do que esse, pois o número das presídias ou das comunidades locais de irmãos e irmãs era superior a cem. A mesa administrativa impunha ao confrade o pagamento da anuidade entre $1 \$ 200$ e $1 \$ 500$ réis - , da entrada (que podia custar $4 \$ 800$ réis) juntamente com a profissão dos votos da Ordem - 8\$400 réis -, cujo rito exigia portar as "contas" (o terço) e a "correia" (ou cinto) - 1\$200 réis -, do capelo ou capuz $\$ 600$ réis. ${ }^{27}$ A concessão de uma patente, ou diploma de identificação, especialmente necessário aos terceiros cujo modo de vida dependia da mobilidade (agentes dos tratos mercantis), custava $\$ 600$ réis. ${ }^{28}$

Os confrades também podiam pagar essas taxas da fraternidade, ou as esmolas costumadas por ocupar as funções prestigiosas da mesa administrativa ou da direção da Ordem²9, com diversos gêneros. Houve irmãs, sobretudo, provavelmente moradoras de comunidades roceiras, que custearam a sua participação na Ordem com panos de algodão, gado, milho, peças de rendas e tecidos manufaturados (AEPNSPOP, OTCOP, Livro Presídia: Cláudio, 1807, Santa Ana do Paraopeba, 1805, Cocais, 1807).

\footnotetext{
${ }^{26}$ Os débitos nominais são mais elevados do que o total das dívidas pendentes, pois incluíam valores não contabilizados - sem o registro corrente de pagamentos efetuados ou registrado como "perdido".

${ }^{27}$ De acordo com os estatutos da Ordem, o novo membro entrava no noviciado e devia permanecer nesse preparatório durante um ano. 0 hábito devia ser lançado quando o devoto era admitido no sodalício (capítulo 14, artigo 6; capítulo 28). Após o período de noviciado, impunha-se ao noviço ou à noviça a profissão. Essa determinação do noviciado, porém, não se tornou costumeira. 0 procedimento comum era cobrar "entrada e profissão", com o lançamento do hábito. Além do comissário da matriz da Ordem, os vicecomissários, nos povoados, também lançavam os hábitos e impunham a profissão aos confrades (ACCOP; OTCOP, Estatutos, 1755; LOPES, 1942, p. 10-11; FORMA de lançar o hábito da Venerável Ordem 3a de Nossa Senhora do Monte do Carmo [...], 1830, p. 3-29). 0 hábito lançado ao noviço, em 1763, constou em livro de presídia, mas o irmão foi dispensado do noviciado em seguida, para exercer a função de vice-comissário (AEPNSPOP, OTCOP, Livro Presídia, Morro do Chapéu, Glória e Dores, 1851).

${ }^{28}$ Os valores foram registrados nos livros de contas das presídias e em correspondência da Ordem (AEPNSPOP, OTCOP, Livro Presídia: Santa Bárbara, 1807; AEPNSPOP, OTCOP, Livro Presídia Morro do Chapéu, 1851; LOPES, 1942, p. 10).

${ }^{29}$ Constam esmolas, em contas de presídia, da ocupação de prioreza, durante dois anos (75\$000 réis), e da função de definidor de mesa, durante um ano (24\$000 réis) (AEPNSPOP, OTCOP, Livro Presídia Morro do Chapéu, 1851).
} 
Além dos pagamentos obrigatórios, os dirigentes das presídias recolhiam as esmolas dos confrades para os sufrágios, ou missas em intenção das almas dos defuntos. Os terceiros, ainda, deixavam em testamento quantias para esse fim e para o pagamento dos débitos atrasados. Por exemplo, na freguesia de Santa Bárbara, o capitão-mor Manuel José Pena (irmão professo desde 1795), devedor de $19 \$ 800$, legou à Ordem, em testamento, $100 \$ 000$, uma quantia que se somaria às suas dívidas passivas (AEPNSPOP, OTCOP, Livro Presídia Santa Bárbara, 1807). As doações em testamentos, comumente com as obrigações de sufrágios, acresciam a arrecadação convencional das presídias e expandiam os créditos do sodalício.

Assim, compreende-se a acumulação dos recursos monetários conservados, em caixa, para os empréstimos a juros ou com penhor, ou para serem convertidos em ofícios litúrgicos ou festivos, edificações e imóveis. O dinheiro (ou ouro em pó ou em barras) guardado no cofre da Ordem, às vezes, era tão significativo que a reputação era de casa bancária, pois servia para contrair empréstimos ou penhorar joias. Um pedido de empréstimo, em nome da fazenda real, foi solicitado pelo governador da capitania de Minas Gerais, em 1766, que pediu à mesa administrativa terciária "todo o cabedal que tiverem" de barra de ouro, pois era preciso arcar com os prementes e "consideráveis pagamentos" da Coroa (LOPES, 1942, p. 97).30

\section{Conclusão}

Sabe-se que, apesar das mudanças econômicas e sociais da crise minerária, as ordens terceiras de Vila Rica, atentas ao decoro dos ofícios divinos - o mais apropriado aos devotos privilegiados -, empenharam-se em edificar templos suntuosos, no estilo rococó, de inspiração palaciana. A suposta decadência das minas do ouro não impediu que a poderosa Ordem Terceira do Carmo construísse sua capela-sede e fizesse os seus negócios, porque, além dos rendimentos auferidos

\footnotetext{
${ }^{30} \mathrm{O}$ governador fez o mesmo pedido à Ordem Terceira de São Francisco de Vila Rica. Lopes transcreveu, ainda, os pedidos de um padre e de um sargento-mor, que propuseram fiança ou hipoteca para obterem os empréstimos (LOPES, 1942, p. 96).
} 
no espaço urbano da capital administrativa das Minas, havia um conjunto de filiais que supria, seguramente, a maior parte das suas necessidades financeiras ou materiais.

A associação plena através das presídias foi um dispositivo eficiente para alcançar os moradores das Minas e estender os incentivos da sociabilidade terciária nas rotas mercantis do território. Efetivou-se, com esse fenômeno da rede (comunicação e solidariedade), uma jurisdição vinculada à Ordem do Carmo de Vila Rica, relacionada à tessitura de fidelidades sociopolíticas entre os devotos, com sentidos hierárquico e comunitário. Supõe-se que houve, notadamente, a integração dos negociantes ou mercadores (com sua reputação de desenraizados), como grupo estamental, à sociedade civil, na medida em que reproduzissem a civilidade político-religiosa, na condição de uma elite das Minas - oficiais militares ou autoridades de governo.

Além dos agentes itinerantes dessa Ordem do Carmo, os confrades dos tratos ou trocas mercantis ajudaram a difundir as práticas corporativas, porque o intercâmbio conferido por sua mobilidade fundava ou alentava a experiência devocional dos fieis. Assim, fundaram-se presídias nos itinerários do circuito mercantil, e o proselitismo terciário, com efeito, alcançou outras capitanias limítrofes do território de Minas Gerais, como as de Goiás e de São Paulo. A confraria atraía (e definia) uma qualidade social projetada na elite dirigente: branca de descendência portuguesa, supostamente não mestiçada, e com capacidade legítima, que lhes parecia exclusiva, para exercer autoridade - cargos do governo camarário, os postos militares e funções eclesiásticas notáveis. Os efeitos econômicos dos investimentos materiais dos confrades, ou das suas doações, na Ordem Terceira de Vila Rica, não foram improdutivos, pois até as ornamentações dos templos, os cultos ou os legados para os sufrágios das almas estimularam as artes mecânicas e liberais e um mercado de bens devocionais ou simbólicos - as insígnias terciárias (escapulários, terços, hábitos, velas), artefatos litúrgicos, alfaias das festas, esculturas, pinturas, gravuras e livros (que não se reduziram às obras de doutrina). Ainda, o capital simbólico e os recursos político- 
religiosos acumulados pelos administradores, presidentes e confrades participantes, traduziram-se na legitimidade do desempenho social do poder e na possibilidade de inserção em uma benéfica rede de crédito e de favores (ainda a se comprovar devidamente). Por fim, o forte dimensionamento corporativo, assim como a transferência de parte das decisões e dos serviços terciários para as presídias, afetaram, decisivamente, a execução da regra religiosa do Carmo e o cumprimento dos estatutos terciários dos setecentos.

\section{REFERÊNCIAS}

ANAIS DA BIBLIOTECA NACIONAL DO RIO DE JANEIRO. Rio de Janeiro: Imprensa Nacional, v. 65, p. 225-231, 1943.

ANDRADE, Francisco Eduardo de. Os pretos devotos do Rosário no espaço público da paróquia, Vila Rica, nas Minas Gerais, Varia Historia, v. 32, n. 59, p. 401-435, 2016.

ARQUIVO DA CASA DOS CONTOS DE OURO PRETO [doravante ACCOP]; PARÓQUIA DE NOSSA SENHORA DO PILAR, ORDEM TERCEIRA DE NOSSA SENHORA DO CARMO DE OURO PRETO [doravante OTCOP]. Estatutos, 1755.

ARQUIVO ECLESIÁSTICO DA PARÓQUIA DE NOSSA SENHORA DO PILAR DE OURO PRETO [AEPNSPOP], OTCOP. Livro Presídia de Nossa Senhora da Conceição da Aplicação de Claudio, 1807.

ARQUIVO PÚBLICO MINEIRO, Secretaria de Governo, códice 224, f. 61-64v.

AUTOS DE DEVASSA DA INCONFIDÊNCIA MINEIRA. 2. ed. Brasília: Câmara dos Deputados; Belo Horizonte: Imprensa Oficial de Minas Gerais, 1982. v. 5, 1982. p. 111.

BARBOSA, Gustavo Henrique. Poderes locais, devoção e hierarquias sociais: a Ordem Terceira de São Francisco de Mariana no século XVIII. 2015. Tese (Doutorado em História) - Universidade Federal de Minas Gerais, Belo Horizonte, 2015.

BAYÓN, Balbino Velasco. História da Ordem do Carmo em Portugal. Lisboa: Paulinas, 2001.

BOSCHI, Caio César. Os leigos e o poder. Irmandades leigas e política colonizadora em Minas Gerais. São Paulo: Ática, 1986.

BOURDIEU, Pierre. A economia das trocas simbólicas. Tradução de Sérgio Miceli et al. São Paulo: Perspectiva, 2007. 
BUSINO, Giovanni. Élite(s) et élitisme. Paris: Presses Universitaires de France, 1992.

CAMPOS, Adalgisa Arantes. As irmandades de São Miguel e as almas do

purgatório: culto e iconografia no Setecentos mineiro. Belo Horizonte: C/Arte, 2013.

CARRARA, Ângelo Alves. Agricultura e pecuária na Capitania de Minas Gerais (1674-1807). 1997. Tese (Doutorado em História) - Universidade Federal do Rio de Janeiro, Rio de Janeiro, 1997.

CARRATO, José Ferreira. [Mapa] Capitania de Minas Gerais nos fins da era colonial. In: CARRATO, Jose Ferreira. Igreja, iluminismo e escolas mineiras coloniais: notas sobre a cultura da decadência mineira setecentista. São Paulo: Companhia Editora Nacional: Editora da Universidade de São Paulo, 1968.

COSTA, Iraci del Nero da. A estrutura familial e domiciliária em Vila Rica no alvorecer do século XIX, Revista do Instituto de Estudos Brasileiros, n. 19, p. 17-34, 1977.

CRUZ, Miguel Dantas da. A nomeação de militares na América portuguesa. Tendências de um império negociado. Varia Historia, Belo Horizonte, v. 31, n. 57, p. 673-710, 2015.

CUNHA, Alexandre Mendes. Espaço, paisagem e população: dinâmicas espaciais e movimentos da população na leitura das vilas do ouro em Minas Gerais ao começo do século XIX. Revista Brasileira de História, São Paulo, v. 27, n. 53, p. 123-128, jan./jun. 2007.

ENCARNAÇÃO, Frei Manuel da. Compêndio da Regra dos Irmãos da Venerável Ordem Terceira de Nossa Senhora do Carmo. Lisboa: Oficina de Miguel Manescal, 1685. p. 118-119.

EVANGELISTA, Adriana Sampaio. Pela salvação de minha alma: vivência da fé e vida cotidiana entre os irmãos terceiros em Minas Gerais - séculos XVIII e XIX. 2010. Tese (Doutorado em Ciência da Religião) - Universidade Federal de Juiz de Fora, Juiz de Fora, 2010.

FONSECA, Paulo Miguel. O contratador João Rodrigues de Macedo: ações e transações através da prática epistolar no século XVIII, Anais da Biblioteca Nacional, v. 125, p. 31-33, 42-45, 2005.

FORMA de lançar o hábito da Venerável Ordem $3^{\text {a }}$ de Nossa Senhora do Monte do Carmo: da profissão, confirmação do prior e absolvição na hora da morte. Ouro Preto: Tipografia de Silva, 1830.

GOMES, Daniela Gonçalves. Ordens terceiras e o ultramontanismo em Minas: catolicismo leigo e o projeto reformador da Igreja Católica em Mariana e Ouro Preto (18441875). 2009. Dissertação (Mestrado em História) - Universidade Federal de Ouro Preto, Mariana, 2009.

HEINZ, Flávio M. Por outra história das elites. Rio de Janeiro: Editora FGV, 2006. 
KANTOR, Íris. A leal Vila de Nossa Senhora do Ribeirão do Carmo. In: DEPARTAMENTO DE HISTÓRIA - ICHS/UFOP. Termo de Mariana: história e documentação. Mariana: Imprensa Universitária da UFOP, 1998.

LIBBY, Douglas Cole. Transformação e trabalho em uma economia escravista: Minas Gerais no século XIX. São Paulo: Brasiliense, 1998.

LOPES, Francisco Antônio. História da construção da igreja do Carmo de Ouro Preto. Rio de Janeiro: Serviço do Patrimônio Histórico e Artístico Nacional/Ministério da Educação, 1942.

MARTINS, William de Souza. Membros do corpo místico: Ordens Terceiras no Rio de Janeiro (c. 1700-1822). São Paulo: Editora da USP, 2009.

MENDONÇA, Nívea Maria Leite. Entre a hierarquia e a devoção: a dinâmica interna e o relacionamento dos Terceiros com a Ordem Carmelita em Minas Gerais (1747-1808). 2015. Dissertação (Mestrado em História) - Universidade Federal de Juiz de Fora, Juiz de Fora, 2015 .

MORAES, Juliana de Mello. Viver em penitência: os irmãos terceiros franciscanos e as suas associações, Braga e São Paulo (1672-1822). 2009. Tese (Doutorado em História) Universidade do Minho, Braga, 2009.

NEVES, Maria Agripina; COTTA, Augusta de Castro. Do Monte do Carmo a Vila Rica: aspectos históricos da Ordem Terceira e da Igreja do Carmo de Ouro Preto. Ouro Preto: Edição da autora, 2010.

OLIVEIRA, Monalisa Pavonne. Fé e distinção: um estudo da dinâmica interna e do perfil de irmãos da Irmandade do Santíssimo Sacramento da Igreja Matriz de Nossa Senhora do Pilar do Ouro Preto (século XVIII). 2016. Tese (Doutorado em História) - Instituto de Ciências Humanas, Universidade Federal de Juiz de Fora, Juiz de Fora, 2016.

PAIVA, Clotilde Andrade. População e economia nas Minas Gerais do século XIX. 1996. Tese (Doutorado em História Social) - Universidade de São Paulo, São Paulo, 1996.

PASSOS, Zoroastro Vianna. Em torno da história de Sabará. Rio de Janeiro: Serviço do Patrimônio Histórico e Artístico Nacional, 1940.

PEDREIRA, Jorge Miguel. Tratos e contratos: actividades, interesses e orientações dos investimentos dos negociantes da praça de Lisboa (1755-1822). Análise Social, Lisboa, v. 31, n. 136-137, p. 355-379, 1996.

PRAT, Frei André. Notas históricas sobre as missões carmelitas no extremo norte do Brasil (século XVII-XVIII). Recife: [s. n.] 1941.

PRECIOSO, Daniel. Terceiros de cor: pardos e crioulos em Ordens Terceiras e Arquiconfrarias (Minas Gerais, 1760-1808). 2014. Tese (Doutorado em História) Universidade Federal Fluminense, Niterói, 2014.

REVISTA DO ARQUIVO PÚBLICO MINEIRO, v. 2, n. 2, p. 321, abril-jun. 1897. 
RODRIGUES, André Figueiredo. Os sertões proibidos da Mantiqueira: desbravamento, ocupação da terra e as observações do governador dom Rodrigo José de Meneses, Revista Brasileira de História, v. 23, n. 46, p. 261-265, 2003.

SALLES, Fritz Teixeira de. Associações religiosas no ciclo do ouro: introdução ao estudo do comportamento social das irmandades de Minas no século XVIII. 2. ed. São Paulo: Perspectiva, 2007.

SANTA ANA, Frei José Pereira de. Crônica dos carmelitas da antiga, e regular observância nestes Reinos de Portugal, Algarves, e seus domínios. Lisboa: Oficina dos Herdeiros de António Pedroso Galram, 1745. Tomo 1, p. 616; 618.

SANTA MARIA, Frei Agostinho de. Santuário Mariano e História das Imagens milagrosas de Nossa Senhora [...]. Lisboa: Oficina de Antônio Pedroso Galram, 1723. Tomo 10. p. 184-185; 234; 245-246.

SILVEIRA, Felipe Augusto de Bernardi. Atuação administrativa e institucional autocéfala: Ordem Terceira do Carmo de Minas Gerais (séculos XVIII-XIX). 2017. Tese (Doutorado em História) - Universidade Federal de Minas Gerais, Belo Horizonte, 2017.

SOUZA, Cristiano Oliveira de. Prestígio, poder e hierarquia: a "elite dirigente" da Venerável Ordem Terceira de São Francisco de Assis (1751-1804). 2015. Tese (Doutorado em História) - Universidade Federal de Juiz de Fora, Juiz de Fora, 2015.

TRINDADE, Raimundo. São Francisco de Assis de Ouro Preto. 2. ed. São Paulo: Revista dos Tribunais, 1958.

VEIGA, José Xavier da. Efemérides mineiras. Belo Horizonte: Centro de Estudos Históricos e Culturais: Fundação João Pinheiro, 1998. 